\title{
Communicative Language Learning and Curriculum Development in the Digital Environment
}

\author{
Sahoon H. Kim ${ }^{1}$ \\ ${ }^{1}$ College of Education, Hankuk University of Foreign Studies, Seoul, Korea \\ Correspondence: Sahoon H. Kim, College of Education, Hankuk University of Foreign Studies, Seoul, Korea. \\ E-mail:kimsh@hufs.ac.kr
}

Received: April 23, 2015 Accepted: May 18, 2015 Online Published: May 22, 2015

doi:10.5539/ass.v11n12p337 URL: http://dx.doi.org/10.5539/ass.v11n12p337

\begin{abstract}
Many schools in non-native English speaking countries are making efforts to implement English Immersed Education (EIE) in order to teach students English in context. Concurrently, the field of education is changing with the rapid evolution of technology, and with teachers and students becoming more technologically adept, ways of teaching and learning are advancing. Computer-supported collaborative learning (CSCL) is readily being applied to second language learning, as technologically rooted activities can provide many benefits to English Language Learners (ELLs). The aim of this study was to explore how the design of collaborative tasks within a virtual environment can enhance ELLs interactive communication, in terms of quality and quantity. First, literature on pedagogical applications of virtual worlds, in a general context and in a language learning context, is explored, as is the notion of cultural relevance and its impact on learning. Design-based methodology was employed, as five different virtual tasks were designed and implemented at Chungwhang Middle School and Indam High School in Seoul, South Korea. Results showed that the amount of interactivity among students and the nature of that interactivity were positively affected through the use of task-based virtual activities. Higher levels of conversation, in terms of quality and quantity, were developed when tasks focused on culture. Thus, further research is suggested on designing culturally relevant quests based on academic content.
\end{abstract}

Keywords: collaborative language learning, curriculum design, digital and smart learning, instructional technology, multicultural education, virtual environments

\section{Introduction}

\subsection{English Immersed Education and Computer-Supported Collaborative Learning}

Schools in many countries are implementing English Immersed Education (EIE) across their curriculums with the rationale of teaching students English in context. This enables learners to think, organize, and share their ideas fluently as well as participate in higher level interactions.

At the same time, computer-supported collaborative learning (CSCL) is being applied to second language learning (Ge, 2011; Lund \& Rasmussen, 2008; Stahl, 2006). Virtual environments that provide chat functions and avatar interaction in 3D environments have been studied as a tool for facilitating collaborative learning (e.g., Baydas et al., 2015; Molenaar et al., 2011; Silseth, 2011; Prensky, 2001). With a growing population of technologically competent students, many researchers have claimed that virtual environments have considerable potential for language learning and teaching (e.g., Luccioni et al., 2015; Thorne \& Reinhardt, 2008). There is great interest in how these environments can be used as part of EIE and how activities can be designed to engage students within content learning in the target language (Lund \& Rasmussen, 2008; Kim, 2011). If tasks were designed for virtual world learning activities in ways that could increase both the quantity and the quality of authentic communication among learners, both language and content learning could be positively impacted.

There have been numerous claims that virtual environments are beneficial to language learning, but there has not been enough empirical evidence about how the virtual world can impact language learning (Kim et al., 2012). This study explores the notion of offering an English-immersed virtual environment for language learning and specific practices about how it can be incorporated into the curriculum development process.

\subsection{Relevant Scholarship}

Many studies of computer-supported collaborative learning for ELLs have been conducted on communicative approaches to second language acquisition. Research on the relationship between computer-mediated 
communication and second language acquisition (SLA) has emphasized how technology has increased learner communication. The focus on the amount of language production has been discussed through SLA theories, as learners' language acquisition capabilities are positively affected by the quantity of their communicative input and output (Krashen, 1982; Swain, 1985). Researchers have claimed that communication, which is understood as a referential exchange of information - a sharing of meaning (Breen et al., 1980; Canale \& Swain 1980; Krashen, 1982), significantly benefits second language acquisition. Therefore, one of the most important factors contributing to successful negotiation of communication is the type of activity (e.g., Fidalgo-Eick, 2001; Smith 2003). However, even though the type of activity, or task, influences the quantity of communication, it is not solely responsible for enhancing communication; other characteristics need to be considered. Thus, it is important to highlight the characteristics of a specific task, rather than one task type or any other primary factor of the learner's negotiation during task-based language learning (Fidalgo-Eick, 2001). More importantly, Zheng and her colleagues argued that culturally relevant curriculum assists ELLs with interaction in virtual environments (Zheng et al., 2009). This, therefore, needs to be further investigated as it relates to task design. From a sociocultural perspective, the context of the tasks can provide further explanation regarding how specific tasks can enhance opportunities to negotiate meaning in second language learning. Therefore, there is a need to investigate how students learn according to the content, culture, and context of a task.

\subsection{Research Design}

In this study, empirical findings were collected from the Collaborative English Language Learning through Avatar (CELLA) program, a English Language Learning (ELL) curriculum that utilized a virtual environment to design, teach, and observe learners. The virtual environment, known as Quest Atlantis (QA, $\mathrm{http} / / / \mathrm{www}$.questatlantis.org/), is a multi-user 3D educational computer game designed to engage middle school children in pro-social, educational tasks (Siyahhan et al., 2012). The first step in the study was to examine the impact of task design on learner interaction. After a pilot study using CELLA, it was realized that simply placing students in an environment and expecting them to engage in collaborative English communication was ineffective. Rather, provocative and engaging student activities needed to be created and completed - tasks that would nurture the production of high-quality communication. Sociocultural theory and the communicative approach to second language learning suggest that tasks designed to nurture rich interaction should have an explicit focus on cultural relevance (Foster \& Ohta, 2005; Watson-Gegeo, 2004), as culturally relevant pedagogical activities have been found to support learning, authenticity, and the development of 21 st century skills (Ladson-Billings, 1995). Therefore, the goal was to create activities within the virtual environment that could accomplish this, research the outcomes of such attempts, and then cycle findings back into the activity design. This design-based approach (Kelly et al., 2014), allowed for simultaneous design and research on learning as it contributed to the curriculum development process. Thus, the aim of the study was to explore how collaborative tasks could be designed for EIE in a virtual environment in order to enhance learners' interactivity, both qualitatively and quantitatively.

\section{Methodology}

\subsection{Program Background}

Within CELLA, QA was chosen as the virtual platform to house learning tasks. QA is a 3D immersive atmosphere with over 50,000 registered members worldwide that allows users to collaborate in virtual environments, as they can engage in educational quests and communicate with others through the use of avatars (Barab et al., 2005). QA is different from other 3D virtual environments because it is designed for educational purposes; it uses game-like tasks and features, and it also has instructional affordances for teachers to offer just-in-time instruction, timely feedback, and customized curricular activities through their flexibly adaptive platform (Thomas, 2005). QA provides English language learners (ELLs) the opportunity to meet native English users. Such interaction between non-native English speakers (NNES) and native English speakers (NES) may help learners increase their comprehensible input (Chen, 2005), which thereby contributes to their second language competence. They also interact with the 3D virtual environment itself and explore the objects in it (Barab et al., 2001), as users are exposed to signs, pop-up messages, and audio in English.

Within QA, the teacher's toolkit allows teachers to assign specific tasks related to their students' work (Thomas, 2005). Tasks include assigning quests to learners, reviewing and evaluating learners' work, assigning points and rewards to learners, and monitoring students' chat and e-mail history. Considering the context, culture, and content of a task is crucial for understanding language learners' negotiation (Watson-Gegeo, 2004; Zheng, 2006). With the toolkit, teachers are able to run their own QA classroom, customizing the experience in ways they find most appropriate for their own context (see Figure 2). 


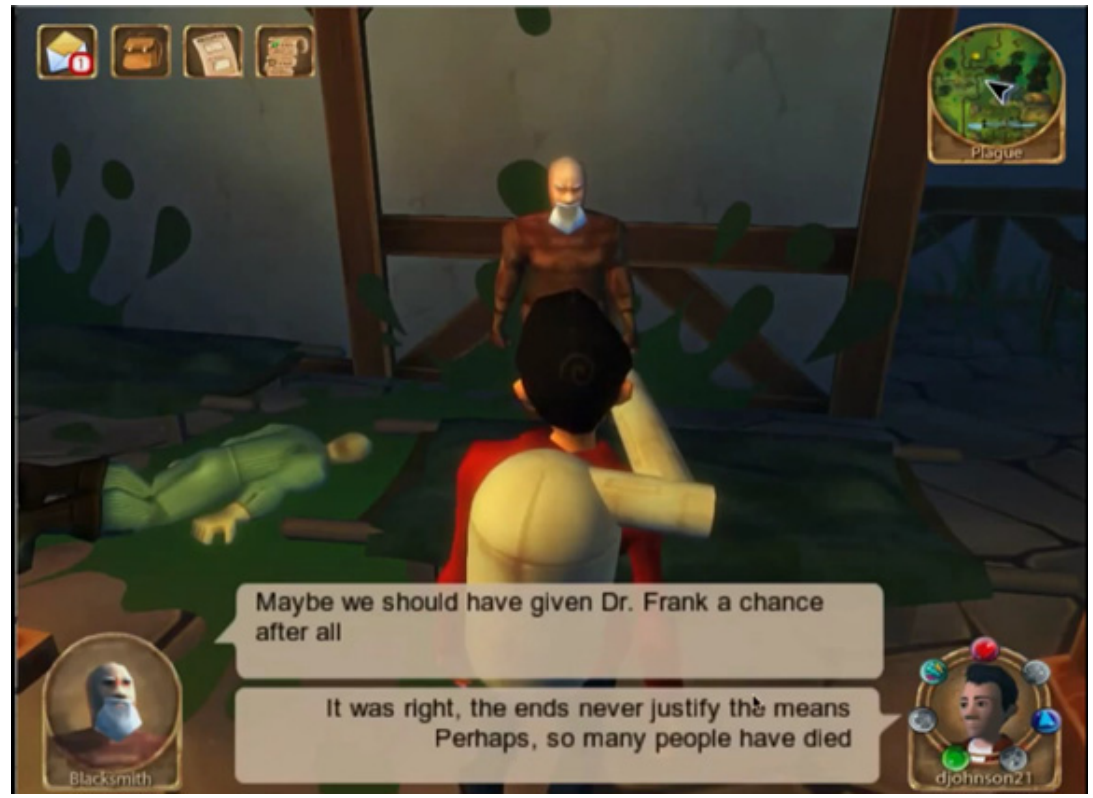

Figure 1. Screenshot of the QA virtual environment
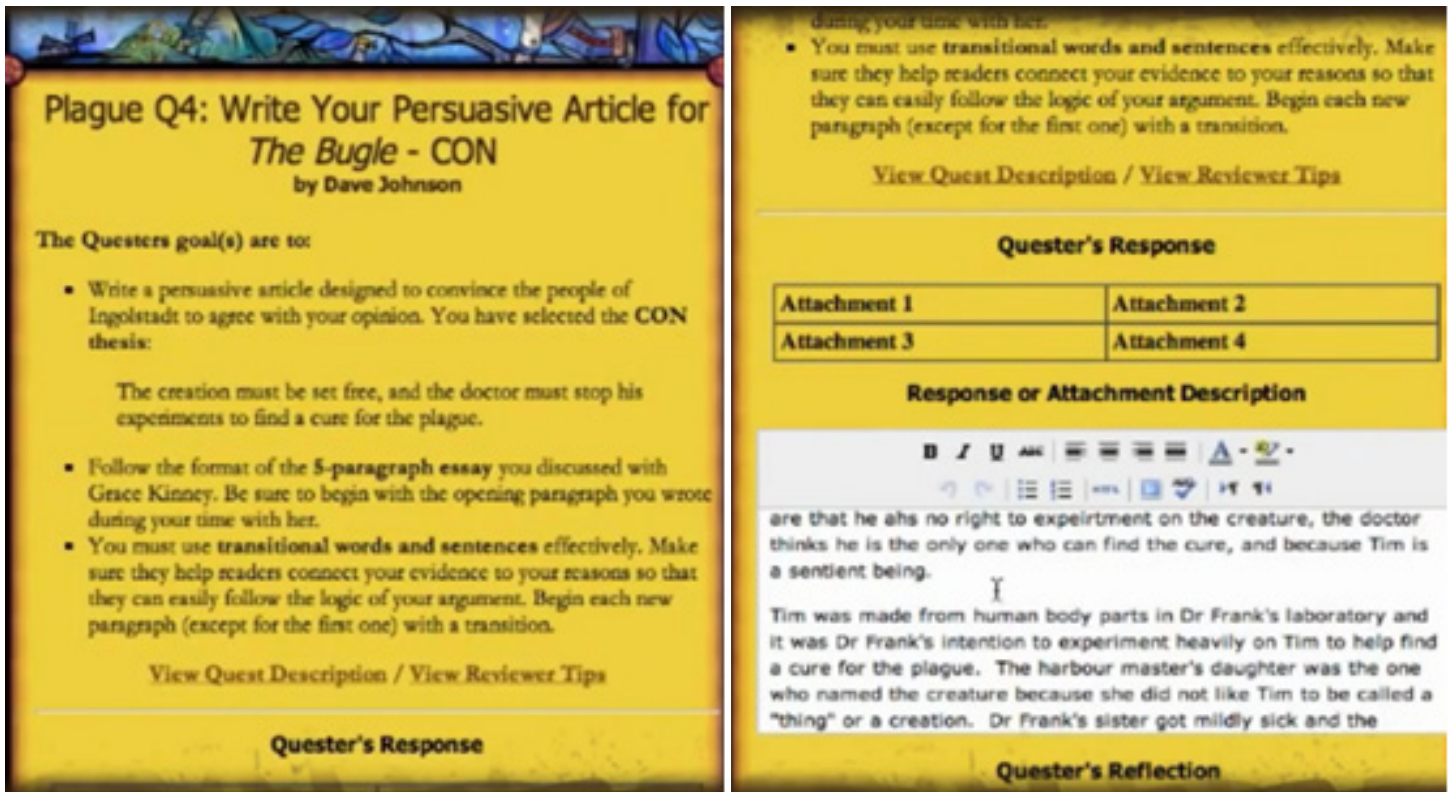

Figure 2. Screenshot of the Teacher's Toolkit (www.questatlantis.org)

\subsection{Data}

\section{a) 2.2.1 Participants and Setting}

The study included 20 participants in naturalistic settings: Ten in Case Study A and 10 in Case Study B. The former took place at Chungwhang Middle School, a public school located in Seoul, South Korea. The first-year middle school students met for two hours per week for 15 weeks, and a total of five quests were completed. The students worked in pairs for computer-supported collaborative English learning. Even when students were outside of the class, they were allowed to $\log$ in to QA using their individual log-in information. The population at this school included very few students who ever lived in English-speaking countries, and all of the students used Korean as their first language. The school opened in February 2010 and only had about 500 students.

Case Study B occurred at Indam High School in Seoul, South Korea. The second-year students met for one hour per week for 15 weeks, and a total of three quests were completed. Students in this case study were also grouped into pairs. Similar to the school in the first case study, Indam High School provided ELL education. 


\section{b) 2.2.2 Data Measures}

Data collection included (1) chat logs from the QA environment, (2) direct observations of students interacting in QA for SLA, (3) participation field notes for learning possible QA phenomena, (4) document analysis of artifacts produced by asynchronous cooperation, and (5) interviews with participants.

\section{c) 2.2.3 Procedures}

In collaboration with the English teachers in the schools and considering the cultural context of the local environments, existing tasks called quests were redesigned. For this study, five quests were redesigned using the QA teacher toolkit: three quests were culturally structured, one was an introduction quest, and one was not specific to culture. The quests were analyzed through the theoretical analysis tool called Communication for Action (see 2.3).

Table 1. Overview of quests

\begin{tabular}{|c|c|c|c|c|c|}
\hline Quest Name & Main Action & Purpose & Characteristic & Case A & Case B \\
\hline $\begin{array}{l}\text { Introduction } \\
\text { (IN) }\end{array}$ & Introduce themselves & $\begin{array}{l}\text { Become accustomed to QA } \\
\text { Use familiar expressions }\end{array}$ & $\mathrm{n} / \mathrm{a}$ & Implemented & \\
\hline $\begin{array}{l}\text { Pop Culture } \\
\text { (PC) }\end{array}$ & $\begin{array}{l}\text { Give examples of pop } \\
\text { culture } \\
\text { Explain reasons for } \\
\text { choosing their examples }\end{array}$ & $\begin{array}{l}\text { Use unfamiliar expressions } \\
\text { Begin culturally relevant } \\
\text { discussions }\end{array}$ & $\begin{array}{l}\text { Culturally relevant } \\
\text { Discussion }\end{array}$ & Implemented & Implemented \\
\hline $\begin{array}{l}\text { Comparing } \\
\text { Culture (CC) } \\
\end{array}$ & $\begin{array}{l}\text { Compare Korean culture } \\
\text { with Western culture }\end{array}$ & $\begin{array}{l}\text { Provide directions } \\
\text { Start discussions } \\
\end{array}$ & $\begin{array}{l}\text { Culturally relevant } \\
\text { Information gap }\end{array}$ & Implemented & Implemented \\
\hline Proverb (ID) & $\begin{array}{l}\text { Interpret unfamiliar } \\
\text { cultural proverbs } \\
\text { Create own cultural } \\
\text { proverb }\end{array}$ & $\begin{array}{l}\text { Increase language } \\
\text { interaction in respect to } \\
\text { culture in different ways }\end{array}$ & $\begin{array}{l}\text { Culturally relevant } \\
\text { Information gap }\end{array}$ & Implemented & \\
\hline Science (SC) & $\begin{array}{l}\text { Discuss Avogadro's law } \\
\text { for explaining why } \\
\text { balloons burst in the sky }\end{array}$ & $\begin{array}{l}\text { Prompt scientific neutral } \\
\text { discussions }\end{array}$ & $\begin{array}{l}\text { Culturally neutral } \\
\text { discussion } \\
\text { (Already learned } \\
\text { content in science class) }\end{array}$ & Implemented & Implemented \\
\hline
\end{tabular}

In the Introduction (IN) Quest, students were asked to introduce themselves to their conversational partner in the QA environment, and each pair presented information about their partner. This task served three purposes: to familiarize students with QA, to give students the opportunity to express familiar things English, and to enable students to improve their writing skills in the CSCL environment.

The Pop Culture (PC) Quest allowed students to discuss Korean pop culture, as they presented and discussed examples and explained their impact. The goal was to motivate students to actively communicate using unfamiliar expressions, though grounded in cultural context. Zheng (2006) asserted that when NES and NNES engage in a culturally driven dialogue and they discuss the non-native speaker's culture, the non-native speaker plays the dominant role in the dialogue. Additionally, students were offered several subtopics to choose from, which in turn, helped them negotiate with each other. Last, given the relevance of the topic, it was projected that students would connect their existing knowledge to the knowledge learned from the dialogue.

The Comparing Culture (CC) Quest built on the strengths and weaknesses of the PC Quest, as modifications were made after the PC Quest's implementation. While the PC Quest successfully guided students beyond the use of fixed form dialogues through choosing familiar cultural topics, students were reluctant to communicate about topics they felt were difficult to discuss in English. Therefore, the CC Quest, an information gap task, was designed for students to compare Korean and American cultures. Because students were familiar with the Korean culture, the modified quest was thought to help students easily share their opinions and substantiate them.

The purpose of Proverb (ID) Quest was to analyze the pattern of language interaction and culture. Unfamiliar proverbs were shown to the students, and they attempted to search for their meaning while engaging in discussions. Additionally, students created their own proverbs that applied to their lives.

The Science (SC) Quest explored student interaction during discussions on neutral topics. The intent was to discover the type of interaction that occurred when students discussed a familiar, neutral topic. The topic chosen, Avogadro's law, was scientific and one that students had previously studied. Middle school students learned 
about it earlier in the year, and high school students learned the rule in middle school and studied it more in high school. It was assumed that students' previous knowledge of this topic would help stimulate English discussions. Thus, the main task of this quest was for students to express their knowledge in English and to accumulate knowledge by cooperating with partners.

In Case B, the structure of the class was similar to that of Case A; however, the high school class schedule was tight and somewhat rushed in comparison to middle school, so two of the five quests were excluded. Considering the students' level and the similarities of the quests, the researchers excluded the IN and ID Quests.

\subsection{Theoretical Analysis}

In this study, design-based research methodology was used (Kelly et al., 2014; Design-Based Research Collective, 2003), as a tool was developed for data analysis based on this approach. The tool used in this research was a system of categories called Communication for Action (CfA). It was created after an inductive process, and the analysis' results were integrated into a systematic coding scheme. The CfA coding scheme was used for this research because it included all of the categories of the traditional communication analysis tool, known as the Negotiation for Meaning (NfM) tool (Pica, 1994; Varonis \& Gass, 1985). The NfM tool included the conversation categories (a) clarification requests, (b) confirmation checks, and (c) comprehension checks. However, Zheng (2006) as well as Foster and Ohta (2005) asserted that the NfM tool was insufficient in terms of its sensitivity for analysis when the sociocultural perspective of learning and ecological psychology is considered. They insisted that in addition to the three conversation categories, negotiation moves, such as assistance and direct pick up triggers should be used (Hall \& Verplaetse, 2000; Watson-Gegeo, 2004; Foster \& Ohta, 2005). They named the new tool Negotiation for Action (NfA) (Zheng et al., 2009).

CfA was developed through the comparison of several empirical analyses of data from earlier analysis tools, including NfM and NfA. Initially, the NfA tool was used, and it not only caused confusion regarding input and output between learners but also provided insufficient distinctive analysis in the data. Thus, it was recognized that only limited meaning could be drawn using the previous tools, and it was, therefore, necessary to modify existing tools. This modification was able to capture interaction between pairs of students, which was not possible using the previous measures. The CfA tool was then used as a lens to view and categorize data. This categorization of codes was accomplished with the use of the qualitative research software package QSR N-Vivo 8.0. The main categories, subcategories, and the codes used for the CfA tool are listed in Table 2.

Table 2. A tool for theoretical analysis

\begin{tabular}{|c|c|c|}
\hline \multicolumn{3}{|c|}{ Communication for Action (CfA) Tool } \\
\hline Main Categories & Subcategories & Codes \\
\hline $\begin{array}{l}\text { 1-Proper } \\
\text { Communication }\end{array}$ & Stages of Content Knowledge & 1-1-Precise social utterance exchange \\
\hline $\begin{array}{l}\text { 1-Proper } \\
\text { Communication }\end{array}$ & Stages of Content Knowledge & 1-2-Precise information exchange \\
\hline $\begin{array}{l}\text { 1-Proper } \\
\text { Communication }\end{array}$ & Stages of Content Knowledge & 1-3-Precise idea exchange \\
\hline $\begin{array}{l}\text { 1-Proper } \\
\text { Communication }\end{array}$ & Stages of Content Knowledge & 1-4-Precise discussion exchange \\
\hline $\begin{array}{l}\text { 1-Proper } \\
\text { Communication }\end{array}$ & Explicit Negotiation Moves & 1-5-Precise direct pick-up exchange \\
\hline $\begin{array}{l}\text { 1-Proper } \\
\text { Communication }\end{array}$ & Explicit Negotiation Moves & 1-6-Precise utterance but co-construction \\
\hline $\begin{array}{l}\text { 2-Communication } \\
\text { Linking }\end{array}$ & $\begin{array}{l}\text { Stages of Content Knowledge } \\
\text { (negotiating actions implicitly through context) }\end{array}$ & 2-1-Incorrect social utterance but proper reaction \\
\hline $\begin{array}{l}\text { 2-Communication } \\
\text { Linking }\end{array}$ & $\begin{array}{l}\text { Stages of Content Knowledge } \\
\text { (negotiating actions implicitly through context) }\end{array}$ & $\begin{array}{l}\text { 2-2-Incorrect information utterance but proper } \\
\text { answer }\end{array}$ \\
\hline $\begin{array}{l}\text { 2-Communication } \\
\text { Linking }\end{array}$ & $\begin{array}{l}\text { Stages of Content Knowledge } \\
\text { (negotiating actions implicitly through context) }\end{array}$ & 2-3-Incorrect idea utterance but proper answer \\
\hline $\begin{array}{l}\text { 2-Communication } \\
\text { Linking }\end{array}$ & $\begin{array}{l}\text { Stages of Content Knowledge } \\
\text { (negotiating actions implicitly through context) }\end{array}$ & $\begin{array}{l}\text { 2-4-Incorrect discussion utterance but proper } \\
\text { reaction }\end{array}$ \\
\hline $\begin{array}{l}\text { 2-Communication } \\
\text { Linking }\end{array}$ & $\begin{array}{l}\text { Explicit Negotiation Moves } \\
\text { (negotiating actions explicitly through communication } \\
\text { break or assistance) }\end{array}$ & $\begin{array}{l}\text { 2-5-Incorrect utterance and clarification request and } \\
\text { proper reaction }\end{array}$ \\
\hline
\end{tabular}




\begin{tabular}{|c|c|c|}
\hline $\begin{array}{l}\text { 2-Communication } \\
\text { Linking }\end{array}$ & $\begin{array}{l}\text { Explicit Negotiation Moves } \\
\text { (negotiating actions explicitly through communication } \\
\text { break or assistance) }\end{array}$ & $\begin{array}{l}\text { 2-6-Incorrect utterance and confirmation check and } \\
\text { proper reaction }\end{array}$ \\
\hline $\begin{array}{l}\text { 2-Communication } \\
\text { Linking }\end{array}$ & $\begin{array}{l}\text { Explicit Negotiation Moves } \\
\text { (negotiating actions explicitly through communication } \\
\text { break or assistance) }\end{array}$ & 2-7-Incorrect utterance and co-construction \\
\hline $\begin{array}{l}\text { 2-Communication } \\
\text { Linking }\end{array}$ & $\begin{array}{l}\text { Explicit Negotiation Moves } \\
\text { (negotiating actions explicitly through communication } \\
\text { break or assistance) }\end{array}$ & 2-8-Incorrect utterance and other-correction \\
\hline $\begin{array}{l}\text { 2-Communication } \\
\text { Linking }\end{array}$ & $\begin{array}{l}\text { Explicit Negotiation Moves } \\
\text { (negotiating actions explicitly through communication } \\
\text { break or assistance) }\end{array}$ & 2-9-Incorrect utterance and self-correction \\
\hline $\begin{array}{l}\text { 2-Communication } \\
\text { Linking }\end{array}$ & $\begin{array}{l}\text { Explicit Negotiation Moves } \\
\text { (negotiating actions explicitly through communication } \\
\text { break or assistance) }\end{array}$ & 2-10-Incorrect direct pick-up trigger and pick-up \\
\hline $\begin{array}{l}\text { 2-Communication } \\
\text { Linking }\end{array}$ & $\begin{array}{l}\text { Explicit Negotiation Moves } \\
\text { (negotiating actions explicitly through communication } \\
\text { break or assistance) }\end{array}$ & 2-11-Having difficulty but trying when encouraged \\
\hline $\begin{array}{l}\text { 3-Communication } \\
\text { Jumping }\end{array}$ & $\begin{array}{l}\text { Stages of Content Knowledge } \\
\text { (negotiation failure without assistance) }\end{array}$ & 3-1-Social utterance and wrong $(\mathrm{NO})$ reaction \\
\hline $\begin{array}{l}\text { 3-Communication } \\
\text { Jumping }\end{array}$ & $\begin{array}{l}\text { Stages of Content Knowledge } \\
\text { (negotiation failure without assistance) }\end{array}$ & 3-2-Information utterance and wrong (NO) answer \\
\hline $\begin{array}{l}\text { 3-Communication } \\
\text { Jumping }\end{array}$ & $\begin{array}{l}\text { Stages of Content Knowledge } \\
\text { (negotiation failure without assistance) }\end{array}$ & 3-3-Idea utterance and wrong (NO) answer \\
\hline $\begin{array}{l}\text { 3-Communication } \\
\text { Jumping }\end{array}$ & $\begin{array}{l}\text { Stages of Content Knowledge } \\
\text { (negotiation failure without assistance) }\end{array}$ & 3-4-Discussion utterance and wrong (NO) reaction \\
\hline $\begin{array}{l}\text { 3-Communication } \\
\text { Jumping }\end{array}$ & $\begin{array}{l}\text { Explicit Negotiation Moves } \\
\text { (negotiation failures with assistance) }\end{array}$ & $\begin{array}{l}\text { 3-5-Having difficulty but giving up even when } \\
\text { encouraged }\end{array}$ \\
\hline $\begin{array}{l}\text { 3-Communication } \\
\text { Jumping }\end{array}$ & $\begin{array}{l}\text { Explicit Negotiation Moves } \\
\text { (negotiation failures with assistance) }\end{array}$ & $\begin{array}{l}\text { 3-6-Incorrect utterance and clarification request but } \\
\text { giving up }\end{array}$ \\
\hline
\end{tabular}

Proper communication is the pattern in which communication is processed with accurate expressions. Four precise utterance exchanges (1-1-1-4) and two negotiation types (1-5-1-6) were analyzed.

Communication linking occurs when some incorrect expressions are delivered. It mainly occurs in conversations that are beyond the speaker's ability in the negotiation-possible range. Implicit communication linking - four implicit negotiation types (2-1-2-4), and explicit communication linking — seven explicit negotiation types (2-5-2-11), were included.

Communication jumping refers to cases where conversation is not coherent because meaning conveyance fails negotiation. It mainly occurs in conversations when speakers attempt to go beyond their expression capacity. Implicit communication jumping-four negotiation failures without assistance (3-1-3-4), and explicit communication jumping - two negotiation failures with assistance (3-5-3-6) were included.

Stage of content knowledge denotes the level of difficulty with respect to content. More complex content knowledge engagement is possible at a more advanced stage of language development. Social utterance (1-1, 2-1, and 3-1), information utterance (1-2, 2-2 and 3-2), idea/opinion utterance (1-3, 2-3 and 3-3), and discussion utterance (1-4, 2-4 and 3-4) were categorized.

Implicit negotiation moves transpire when negotiation for action occurs indirectly, as users respond accurately after recognizing their counterpart's intention. As a result, continuous conversation with the counterpart starts through content, culture, and context knowledge.

Explicit negotiation moves occur when the partner's utterance has a direct effect on the negotiation process. Clarification requests, confirmation checks, comprehension checks, co-construction, self-correction, other-correction, direct pick-up, and encouragement are all examples.

Negotiation trying refers to instances when a speaker tries to explicitly negotiate an incorrect expression (2-5-2-11, and 3-1-3-6).

Using the analysis tool, the quantity of the CfA, which is the meaningful conversation happening per task as communication coded in all categories, was measured and compared. Second, communication characteristics were highlighted through patterns of communication. Proper communication is goal-directed conversation on the level at which students make correct expressions and respond to them. Communication linking is conversation that is "a little bit beyond" their ability. Sentences that cannot be correctly constructed are divided into one form negotiated implicitly and another form negotiated through communication breaks or assistance, which depends on the context or content. Communication jumping takes place when students go beyond their power of expression and therefore the conversation topic derails. This case is sectioned into failure of implicit negotiation 
and that of negotiation despite a response by the counterpart. Third, it is possible to study the stage of content knowledge that the learner expresses in English within each task. By dividing the learners' expressions into stages ranging from social expression to discussion utterance, this study sought to explain the interrelation of the stage of knowledge according to task.

\section{Results and Discussion}

\subsection{Case Study A: Chungwhang Middle School}

\section{d) 3.1.1 Introduction Quest}

The chat log was analyzed using CfA for quantity of language output, communication patterns, the stages of content knowledge, and the types of negotiation moves. In this quest, 163 interactions were coded, representing $20 \%$ of the total, indicating active communication.

The analysis of the communication patterns showed that $61 \%$ of the communication was classified as precise sentences and proper responses. Approximately $29 \%$ was categorized as examples of the conversation carrying on with incorrect sentences, and $10 \%$ of the communication was coded as "failed conversation." Of all the quests, this one had the highest rate of proper communication. Among the three stages of content knowledge, information-related utterances were the highest (78\%) using proper communication (see Table 3). An example from the chat log shows communication patterns used in the IN Quest.

Sieun: What's your name? (precise information asking)

Subin: my name is subin (proper answer; 1-1 precise information exchange)

Subin: where are you from? (precise information asking)

Sieun: I'm from KOREA (proper answer; 1-1 precise information exchange)

Sieun: Do you have brother? (precise information asking)

Subin: yes. (proper answer, 1-1 precise information exchange)

Do you have brother? (precise information asking)

Sieun: Yes. (proper answer; 1-1 precise information exchange)

How old is your brother? (precise information asking)

Subin: 18. (proper answer; precise information exchange)

The analysis of the stages of content knowledge that students used in the dialogue revealed that they usually spoke in precise sentences when they shared information about daily life, which they had learned in school. Thus, they were only able to talk about things they had learned in fixed forms. If one partner used an incorrect sentence, the other could still respond to it based on memory. Most of the topics addressed were simplistic, such as favorite color, hobby, and food.

Table 3. Results of middle school students' introduction quests

\begin{tabular}{cccccc}
\hline & $\begin{array}{c}\text { Proper } \\
\text { Communication }\end{array}$ & $\begin{array}{c}\text { Communication } \\
\text { Linking }\end{array}$ & $\begin{array}{c}\text { Communication } \\
\text { Jumping }\end{array}$ & Total & Percentage \\
\hline Information Exchange & 54 & 17 & 2 & 73 & $78 \%$ \\
Idea Exchange & 14 & 2 & 4 & 20 & $22 \%$ \\
Discussion Exchange & 0 & 0 & 0 & 0 & $0 \%$ \\
Total & 68 & 19 & 6 & 93 & $100 \%$ \\
\hline
\end{tabular}

Also, despite students' English proficiency levels, they did not have difficulty introducing themselves. Communication was mostly accurate, and proper answers were given in response to questions. Last, dialogues were mostly associated with sharing information, so students did not have the opportunity to introduce original ideas or opinions. Discussions never occurred between students, as most did not ask follow-up questions but instead accepted the other's statement.

From this quest, a few implications can be drawn. It is important to give students familiar topics to get them to actively talk to one another, as they communicate more when the topic is familiar. Conversely, a quest about something new is also needed to break students from fixed forms learned in English classes. Finally, the quest has to be designed to encourage students to say what they think and not just ask them to provide basic information. 


\section{e) 3.1.2 Pop Culture Quest}

Compared to the IN Quest, the quantity of communication decreased in the PC Quest, and students used fewer familiar sentences. This led to an increased rate of communication linking and jumping, yet it stimulated higher level thinking.

Table 4. Results of middle school students' Pop Culture Quests

\begin{tabular}{cccccc}
\hline & $\begin{array}{c}\text { Proper } \\
\text { Communication }\end{array}$ & $\begin{array}{c}\text { Communication } \\
\text { Linking }\end{array}$ & $\begin{array}{c}\text { Communication } \\
\text { Jumping }\end{array}$ & Total & Percentage \\
\hline Information Exchange & 24 & 14 & 4 & 42 & $41 \%$ \\
Idea Exchange & 18 & 20 & 8 & 46 & $45 \%$ \\
Discussion Exchange & 3 & 5 & 7 & 15 & $15 \%$ \\
Total & 45 & 39 & 19 & 103 & $100 \%$ \\
\hline
\end{tabular}

The rate of idea-related utterances increased significantly (45\%) in comparison to the previous quest. Students communicated their own thoughts as well as direct facts. Even though incorrect sentences were prevalent, students tried to express themselves and worked hard to understand one another without using fixed phrases.

Sieun: What do you do with mobile phone much? (incorrect idea; asking: What do you usually do with your mobile phone?)

Jihyun: I send some message to my friend (proper answer: I usually use my mobile phone to send messages to my friend; 2-3-incorrect idea utterance but proper answer)

Sieun: ah What does it inflence to your life? (incorrect discussion utterance)

Jihyun: ......(having difficulty; no answer)

Jihyun: How about you? What pop culture do you like? (3-4-discussion utterance and wrong (NO) reaction)

The results showed there was little opportunity for active discussion. Only $15 \%$ of the interactions were coded as "discussion exchange." Therefore, most of the interactions were simple exchanges of information or ideas. Indeed, most communication jumping was found at the discussion level. The following student interview illustrates this phenomenon.

Researcher: You hardly talked about the effects of pop culture on society. Were you having a difficult time explaining the impact?

Siyeon: No. We already learned about it and had a debate over the topic, such as effect of drama on psychology of adolescence or fan's attitude for celebrity in a class.

Researcher: Why did you not talk about it in the quest?

Siyeon: Sir! I also feel easier in saying of it in Korean but it is hard to explain that in English. I don't know how to start.

Researcher: Do you mean that it is hard to talk about it in English?

Siyeon: Partly true. Jihyun and I all knew about it but I felt a little bit trouble in saying that in English. So, we just talk about what we can.

Students felt it was difficult to express their own thoughts on a topic regardless of their knowledge about it. In this respect, the quest needed to be redesigned to stimulate learners' natural discussion.

f) 3.1.3 Comparing Culture Quest

Table 5. Results of middle school students' Comparing Culture Quests

\begin{tabular}{cccccc}
\hline & $\begin{array}{c}\text { Proper } \\
\text { Communication }\end{array}$ & $\begin{array}{c}\text { Communication } \\
\text { Linking }\end{array}$ & $\begin{array}{c}\text { Communication } \\
\text { Jumping }\end{array}$ & Total & Percentage \\
\hline Information Exchange & 16 & 18 & 3 & 37 & $23 \%$ \\
Idea Exchange & 25 & 34 & 19 & 78 & $48 \%$ \\
Discussion Exchange & 7 & 21 & 19 & 47 & $29 \%$ \\
Total & 48 & 73 & 41 & 162 & $100 \%$ \\
\hline
\end{tabular}


The CC Quest was the highest rated, accounting for 229 CfA codes (29\%), making it the most active. Communication linking was the most common communication pattern (48\%), as students tried to make original sentences when they made comparisons between the two cultures.

As shown in the table above, idea exchange occurred in proper communication and in communication linking with the greatest frequencies, generating considerably more idea exchange than information exchange. Even though the discussions consisted of mostly incorrect sentences, higher level expressions were formulated, as seen in the following chat log.

Sieun: Frankly, I like American's more. Because it is hot or sweet. How about you?

Jihyun: me too;;; but korean food is good for our health (1-3-precise idea exchange)

Sieun: Yes, But my body (?) likes hot and sweet foods more than healthy food. (incorrect discussion utterance)

Jihyun: me too.. because we like eat junk food.. Because that can make easy (an additional example; incorrect discussion utterance)

Sieun: Yes, it can save time. (proper answer; 2-4-incorrect discussion utterance but proper reaction)

Jihyun: so we can eat break time. that's good in american's food (incorrect discussion utterance)

Sieun: Of course. (proper answer;2-4-incorrect discussion utterance but proper reaction)

Sieun: but there are many bad things. It is unhealthy. (an additional counterexample)

Jihyun: yes that is bad one (proper answer; 1-4-precise discussion exchange)

Sieun: However!! I like americans' more.

Whether communication linking or jumping, communication beyond the learner's ability played an important role. Students tried to use less familiar sentences to explain American culture, and debates occurred as students shared opinions. Even though the sentences were incorrect, students tried their best to express their thoughts. The following interview shows that culturally relevant tasks can trigger deeper communication and stimulate discussion of indirect experience.

Jihyun: When I introduced myself, I just said about what I already knew. It was boring a little bit. As to the scientific topic, I had no idea of it. Comparing cultures was very fit into the English topic. First, I started seeking daily life in South Korea and guess Americans' life corresponding to Korean. It naturally made me talk about why there is difference between them.

Researcher: Your life triggered curiosity, didn't it? By the way, did you also like Korean pop culture?

Jihyun: Well, you know, I felt trouble in relating pop culture to my daily life. It felt as if it is none of business to think about the impact of pop culture on me. And it is so hard to talk about it in English.

Researcher: Do you think that you can say about it in English, because it was associated with your culture, though you had no idea of it?

Jihyun: Yes, it is. There are many things to talk about in English around us, such as school life and food. Thus, I could naturally compare them and talk about them in English. I guess Korean has more apartments and the United State has more houses, which might result from relative size of two countries, right?

Researcher: Sometimes, you were not able to express your thoughts in English. Does it make you feel troubled?

Jihyun: I did my best to convey what I want to say. But from time to time, I failed to make something.

Researcher: What kind of thing?

Jihyun: I wanted to tell why American did not distinguish words for the elderly from words for the younger. But I couldn't.

The CC Quest provided a topic that helped students actively give their opinions and use new sentences. Students shared specific examples through their knowledge of South Korean culture, and this allowed them to explore the less familiar American culture and helped them to actively make comparisons between the two cultures. 


\section{g) 3.1.4 Proverb Quest}

Results showed that the quantity of communication ranked second highest, following the CC Quest, and the rate of communication linking was almost the same (41\%) as that of the CC Quest (48\%). This showed that participants eagerly expressed their opinions without using fixed form dialogue, and they tried to create sentences that actually expressed their thoughts.

\section{h) 3.1.5 Science Quest}

The results showed that the students were incapable of explaining the scientific phenomenon, and the quest yielded a decreased amount of conversation. Only $9 \%$ of the interactions were coded as "communication for action." Similarly, the rate of communication jumping rose sharply, which was associated with avoidance of the topic. A detailed analysis of the conversation showed that students spent most of the time in social activity rather than in any discussion of the content. The only discussion that focused on the topic was about the balloon bursting. Students could not explain the rationale for the balloon bursting and would not attempt to discuss it, as indicated by the high rate of abandonment.

Eunsol: $i$ made the balloon fly too.

Eunsol: actually it disappeared (1-2-precise information exchange)

Subin: $i$ wonder why it disappeared

Eunsol: me too

Subin: so we should find the reason (precise idea asking)

Eunsol: NOW??? (having difficulty)

Subin: yes let's start (encouraging)

Eunsol: BUT time is over... Let's don't do that kk It is so hard (3-5- having difficulty and encouraging but giving up)

The students already knew that balloons burst at high altitude. Thus, it was thought that they avoided discussing the reasons by conversing in relatively simple expressions such as "we have heard our science teacher" or "I experienced."

The researcher: Eunsol, you rarely talked about the science work in comparison to other ones. Even, a result has not been submitted.

The student: It is ridiculous. You have required too much work found impossible.

The researcher: Why not? You have known all about it. Isn't it the simple reason that the pressure decreases when the balloon goes up and the increasing bulk causes the balloon to burst?

The student: I don't know. It was really really hard.

This interview excerpt shows that students found it very difficult to express the content of the quest in English, even though they were familiar with the material. While they could have conversations on personal experience despite unfamiliarity, they refused to converse about the scientific content.

i) 3.1.6 Findings from Case $\mathrm{A}$

It should be noted that reflection and modification were an important part of this study. During the implementation of the questions, careful reflection occurred and necessary modifications were made to the subsequent quests. In correlation to the content of the quests, learners' collaborative English communication showed differences regarding amount of discussion, communication pattern, and knowledge construction.

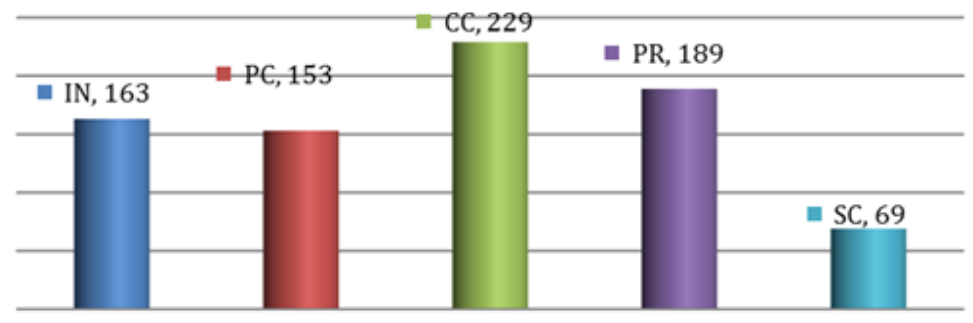

Figure 3. Comparison of communication for action according to middle school students' quests 
The general quantity of the CfA generated by students in this curriculum design is indicated in Figure 3 . The quests with the largest participants, $\mathrm{CC}$ and PR, took a culturally relevant approach and provided a procedure to bridge the gap between a familiar culture and an unfamiliar one. Students generated more active conversations while guessing about unfamiliar cultural content based on what they were accustomed to. They found meaning in new conversational topics by filling in the gaps, rather than by simply regurgitating familiar ones through a one-sided process.



Figure 4. Comparison of communication patterns in middle school students' quests

The patterns of conversation were categorized by quest. The IN Quest engaged students, as students delivered their own information precisely and understood their partners. This process showed standard patterns in conversation and resulted in the most accurate communication. In the PC Quest, information delivery and idea exchange were the most frequent patterns of communication. The students generated a number of new expressions when providing examples. Despite some incorrect sentences, expressions were understood because of commonly shared cultural knowledge, which led to further conversation. When making comparisons in the CC Quest, different ideas were suggested, resulting in a sharp drop in proper communication. The students used unfamiliar expressions in the process of exchanging opinions.

This result was similar to that of the ID Quest; however, both of these tasks could not bring about an active discussion level, resulting in communication jumping or failure. The SC Quest led to the least amount of communication. Even though detailed and experiential opinions about scientific facts were expressed, it was almost impossible for the students to present them as scientific knowledge.

\subsection{Case Study B: Indam High School}

Three of the five quests were implemented in Case Study B: the PC, CC, and SC Quests. These quests were chosen because they each yielded active communication in the previous case study, and they included both culturally relevant and non-culturally relevant concepts, which emerged as an important issue in Case Study A. The two case studies yielded similar results, yet the high school case generated some additional findings.

\section{j) 3.2.1 Pop Culture Quest}

The amount of conversation generated through the PC Quest was approximately $30 \%$ of the whole conversation and yielded a great deal of communication. The most frequent patterns were proper communication with 87 instances (38\%) and communication linking with 96 instances (42\%). Students were able to explain reasons for their choices and consider societal effects with very little difficulty. The conversation also naturally flowed as students asked about their counterparts' opinions and made arguments in response to one another, rather than simply requesting objective facts or offering didactic information. Whereas the middle school students exchanged information to the extent in which they favored a certain pop culture or their favorite singers, actors, or TV shows, the high school students discussed their preference for pop culture and its impact on society. That is, they engaged in the conversation that the quest aimed for and accumulated information in English in an advanced way.

As for stages of content knowledge through conversation, the students moved their conversations without any significant issues during the stages of information and idea exchange. However, when they turned to actual discussion, communication jumping occurred. While the students did not have difficulty presenting their opinions based on information exchange during English conversation, there was some failure to deliver opinions when it came to constructing an argument. 
Even though students had hoped to meet NES who logged in to the virtual world and they recognized that there had been many chances to solve the quest in collaboration with them, they did not communicate with NES to solve the quest.

\section{k) 3.2.2 Comparing Culture Quest}

In the CC Quest, CfA accounted for approximately $50 \%$ of the conversation. Students tried to make precise expressions that were beyond their ability in 130 instances (40\%) of communication linking and 71 instances $(22 \%)$ of communication jumping.

The most interesting finding was that students voluntarily contacted other QA users to learn about the American culture. Many NES were also interested in learning about a different culture and actively joined in the information exchange. This led to continuous participation with NES and increased communication for action in the virtual environment. The following example shows how native and non-native speakers virtually interacted.

Jingdong (NNES): hey wombat.

Jingdong: can you help us with a quest? (precise social utterance)

wombat1 (NES): what quest? (proper answer)

Jingdong: we are comparing Korean culture and other culture.

Jingdong: So we need someone who can tell about other culture. (precise information utterance)(..ellipsis)

Jingdong: where do you live? (precise information utterance)

wombat1: austrailia (proper answer)

Jongsoo: oh!! i ve been there!!! (precise social utterance)

Jingdong: what's so awful about school? (precise information utterance)

wombat1: almost everything? (clarification request)

Jingdong: erm.... do you go to school early? (precise information utterance)

wombat1: no (proper answer)

Jingdong: what time? (precise information utterance)

wombat1: 9 (proper answer)

Jingdong: wow

Jingdong: what time does school end? (precise information utterance)

wombat1: 3 (proper answer)

Jingdong: the school $i$ go to,...

Jingdong: we start class at 8:20 and ends at 4 (self-correction)

wombat1: wow!!!!!!!!!!!!!!!!!!!!!!!!!!!!!!!!!!!!!!!!!!!!!!!!!!!!

Jingdong: it's nothing great

Table 7. Comparative activity analysis for high school students

\begin{tabular}{llll}
\hline Cases & Formal Activities & Mixed Activities & Informal Activities \\
\hline High School & $62 \%$ & $28 \%$ & $10 \%$ \\
\hline
\end{tabular}

This phenomenon was analyzed intensely, and learners' collaborative activities were divided into three categories: formal activities, mixed activities-which took place unintentionally through the formal virtual education program, and informal activities - which were not related to the allotted tasks and took the form of free conversation from students logged in to the virtual world. As shown in Table 7, most of the mixed activities occurred in the CC quest, and the quantity of communication shown for one topic was far more than those in informal activities that were allotted more time. Since the students who tried to communicate with NES during the mixed activities had their own reasons and topics for the conversations, different conversations occurred than those that arose from the purely informal activities. Indeed, the analysis of the conversation patterns with NES in informal activities showed that the communication was focused more on delivering factual information than on 
exchanging opinions; nevertheless, through the mixed activities, students tried to seriously discuss cultural differences. Still, the stage of constructing knowledge was mostly acquired through chatting with classmates in formal language.

\section{1) 3.2.3 Science Quest}

The quest resulted in the least conversation, showing same results as in Case A. However, while middle school students could not communicate at all, high school students were able to hold a conversation. Although the analysis showed that the communication patterns were similar to those of other quests (see Figure 5), it was concluded that the high school students were able to discuss the scientific rule and express themselves.



Figure 5. Communication patterns of SC Quest for high school students

Translating science vocabulary from Korean to English was not an obstacle. The students were accustomed to using a computer and found answers using an internet dictionary. Information exchange was the main knowledge accumulation step, and there was rarely an argument during the idea exchange.

The communication patterns were similar to other quests, and the reason for less conversation was that the topic did not trigger extensions. Students only focused on giving the correct answer. The conversation developed without discussing experiences, ideas, or values.

It can be argued that for the high school students discussing scientific topics in English was not impossible. Yet, it was challenging for students to build rich communication in a context that did not have a close relationship to their daily life. Cultural context becomes a triggers for conversation and leads to more, whereas scientific topics presented in isolation from culture did not prompt plentiful communication in terms of stimulating excitement and developing ideas. Thus, cultural relevance is key.

\subsection{Findings from Cross Case Analysis}



Figure 6. Quantity (CfA) according to quests and analysis of communication patterns 
Collaborative language learning in QA encouraged natural language learning by stimulating students to use English in context through activity quests. This process was different from regular English classes because language was not directly taught - students used English with others to simultaneously express their opinions, accumulate new knowledge, and fix usage errors. Since this process of language acquisition focused on meaning and not form, the content of the tasks had a great effect on the quantity and quality of the conversation. The quantity and patterns of communication that were discovered is shown in Figure 6.

As for the quantity of communication, shown in the bar graphs in Figure 6, the communication of culturally relevant content yielded far more conversation than the value-neutral science task for both cases. In particular, the most conversation occurred in the $\mathrm{CC}$ task, which required the students to overcome cultural gaps in the virtual world. Nevertheless, the comparing processes were different in the two cases. The middle school students identified, recalled, and compared the functions and meanings of culture, while the high school students sought support from NES in the virtual world. The unfamiliar information, the American culture, became a trigger for them to seek NES to acquire the information, exchange ideas, and engage in discussion.

In terms of quality of conversation, gaps were found between the cases, shown in the line graphs in Figure 6 . While high school students maintained a consistent pattern of conversation, middle school students' conversation patterns varied depending on the quests. Middle school students reacted sensitively to the content of the quests; whereas the high school students' communication depended on the content rather than the level of difficulty. Furthermore, the scientific content should have been presented in ways that were culturally relevant and not isolated from the notion of culture. One student made the following remarks:

"The conversation about the science topic seemed like an answer seeking. While the comparing culture quest helped me to share and develop ideas through many talks with counterparts, the science one had the fixed answer. The reason was not important during idea exchange, wasn't it? It was alright to explain it in the theory, which had no necessity of communication. It was so boring and strict."

From the comparison analysis, it was found that all of the students generated a higher level and a higher quality of English conversation during the culturally relevant quests.

The middle school students, who had different communication patterns according to the content and who needed better English skills to survive in the virtual world, found the culturally relevant comparison task helpful in communicating. It also helped to promote conversation with the high school students. The fact that the information gap between the different cultures provided the students with opportunities to approach NES in the virtual world suggests a point for further research. Additionally, a clear next step in this field is to design culturally relevant quests in academic content. This will hopefully yield conversations about science content that are rich in terms of both quantity and quality. Being that virtual worlds are environments where diverse cultural groups coexist, culturally relevant curriculum design proposes not only language learning but also the necessity of interdisciplinary research.

\section{Conclusion}

Miller and her colleagues argue that for active collaborative learning, it is important not to relinquish structure along with control to avoid learner frustration (Miller et al., 1996). In a traditional class, because teachers maintain control of the procedures, it is comparatively easier for the instructor to regulate learners' activity. However, in a collaborative learning situation, especially in a virtual environment where agents can encounter unexpected situations, it is important to design structured activities so that learners can take control of their own learning and negotiate meaning in ways that are genuinely collaborative. The practical recommendation for how an instructor can use a virtual environment is not to simply offer an English-immersed setting but to structure it in a nuanced and culturally relevant way. Previous studies argue that the most critical elements in constructing collaborative learning situations are designing an appropriate learning task so that students actively engage in the task (e.g., Barkley et al., 2005). In the SLA field, task-based learning theorists also support this point.

If the primary purpose for introducing a virtual world for English education is to promote student interactivity, the educational content used for this purpose must be carefully conceptualized in terms of culture. This allows students to produce conversation beyond their ability, enabling them to fully express their ideas. Since this study showed that students are able to understand one another even when they produce statements that are not be entirely accurate, they should be given opportunities to discuss complex topics in ways that increase the quantity of their output and the depth of their discussion, regardless of errors in syntax and vocabulary. This may be accomplished by way of culturally relevant content tasks. When task-based learning is combined with culturally relevant activities, the virtual environment becomes a place of teaching and learning. 


\section{Acknowledgements}

This work was supported by Hankuk University of Foreign Studies Research Fund of 2015.

\section{References}

Barab, S., Thomas, M., Dodge, T., Carteaux, R., \& Tuzun, H. (2005). Making learning fun: Quest Atlantis, a game without guns. Educational Technology Research and Development, 53, 86-107. http://dx.doi.org/ 10.1007/BF02504859

Barab, S. A., Hey, K. E., Barnett, M., \& Squire, K. (2001). Constructing virtual worlds: Tracing the historical development of learner practices. Cognition and Instructions, 19, 47-94. http://dx.doi.org/ 10.1207/S1532690XCI1901_2

Barkley, E. F., Cross, K. P., \& Major, C. H. (2005). Collaborative learning techniques: A handbook for college faculty. San Francisco: Jossey-Bass.

Baydas, O., Karakus, T., Topu, F. B., Yilmaz, R., Ozturk, M. E., \& Goktas, Y. (2015). Retention and flow under guided and unguided learning experience in 3D virtual worlds. Computers in Human Behavior, 44, 96-102. http://dx.doi.org/10.1016/j.chb.2014.11.041

Breen, M. P., \& Candlin, C. N. (1980). The essentials of a communicative curriculum in language teaching. Applied Linguistics, 1(2), 89-112. http://dx.doi.org/10.1093/applin/I.2.89

Canale, M., \& Swain, M. (1980). Theoretical bases of communicative approaches to second language teaching and testing. Applied Linguistics, 1(1), 1-47. http://dx.doi.org/10.1093/applin/I.1.1

Chen, Y. H. (2005). Computer mediated communication: The use of CMC to develop EFL learners' communicative competence. Asian EFL Journal, 7(1), 167-182.

Design-Based Research Collective. (2003). Design-based research: An emerging paradigm for educational inquiry. Educational Researcher, 32(1), 5-8. http://dx.doi.org/doi: 10.3102/0013189x032001005

Fidalgo-Eick, M. (2001). Synchronous on-line negotiation of meaning by intermediate learners of Spanish. Doctoral dissertation. The University of Iowa, Iowa City, IA.

Foster, P., \& Ohta, A. S., (2005). Negotiation for meaning and peer assistance in second language classrooms. Applied Linguistics, 26(3), 402-430. http://dx.doi.org/10.1093/applin/ami014

Ge, Z.-G. (2011). Exploring e-learners' perceptions of net-based peer-reviewed English writing. International $\begin{array}{llll}\text { Journal of Computer-Supported Collaborative Learning, } & \text { 6(1), }\end{array}$ http://dx.doi.org/10.1007/s11412-010-9103-7

Hall, J. K., \& Verplaetse, L. S. (2000). Second and foreign language learning through classroom interaction. Mahwah, NJ: Lawrence Erlbaum.

Kelly, A. E., Lesh, R. A., \& Baek, J. Y. (2014). Handbook of Design Research Methods in Education: Innovations in Science, Technology, Engineering, and Mathematics Learning and Teaching. Taylor \& Francis.

Kim, S. H. (2011). An instructional design for an integrated English language curriculum with $3 D$ virtual world affordances. Doctoral dissertation. University of Wisconsin, Madison, WI.

Kim, S. H., Lee, J. L., \& Thomas, M. K. (2012). Between purpose and method: A review of educational research on 3D virtual worlds. Journal of Virtual Worlds Research, 5(1), 1-18. http://dx.doi.org/10.4101/jvwr.v5i1.2151

Krashen, S. D. (1982). Principles and practice in second language acquisition. Oxford, UK: Pergamon.

Ladson-Billings, G. J. (1995). Toward a theory of culturally relevant pedagogy. American Education Research Journal, 35, 465-491. http://dx.doi.org/10.3102/00028312032003465

Luccioni, A., Benotti, L., \& Landragin, F. (2015). Overspecified references: An experiment on lexical acquisition in a virtual environment. Computers in Human Behavior, 49, 94-101. http://dx.doi.org/10.1016/j.chb.2015.02.036

Lund, A., \& Rasmussen, I. (2008). The right tool for the wrong task? Match and mismatch between first and second stimulus in double stimulation. International Journal of Computer-Supported Collaborative Learning, 3, 387-412. http://dx.doi.org/10.1007/s11412-008-9050-8

Miller, J. E., Groccia, J. E., \& Wilkes, J. M. (1996). Providing structure: The critical element. In T. E. Sutherland 
\& C. C. Bonwell (Eds.), Using active learning in college collaborative learning classes: A range of options for faculty (pp. 17-30). New Directions for Teaching and Learning, No. 67. San Francisco: Jossey-Bass.

Molenaar, I., Chiu, M. M., Sleegers, P., \& van Boxtel, C. (2011). Scaffolding of small groups' metacognitive activities with an avatar, International Journal of Computer-Supported Collaborative Learning, 6, 601-624. http://dx.doi.org/10.1007/s11412-011-9130-z

Pica, T. (1994). Research on Negotiation: What Does It Reveal About Second-Language Learning Conditions, $\begin{array}{llll}\text { Processes, and } \quad \text { Outcomes? } & \text { 4anguage }\end{array}$ http://dx.doi.org/10.1111/j.1467-1770.1994.tb01115.x

Prensky, M. (2001). Digital game-based learning. New York: McGraw-Hill.

Silseth, K. (2011). The multivoicedness of game play: Exploring the unfolding of a student's learning trajectory in a gaming context at school. International Journal of Computer-Supported Collaborative Learning, http://dx.doi.org/10.1007/s11412-011-9132-x

Siyahhan, S., Barab, S. A., \& Downton, M. P. (2012). Using activity theory to understand intergenerational play: The case of Family Quest. International Journal of Computer-Supported Collaborative Learning, http://dx.doi.org/10.1007/s11412-010-9097-1.

Smith, B. (2003). Computer-mediated negotiated interaction: An expanded model. Modern Language Journal, 87, 38-57. http://dx.doi.org/10.1017/S027226310426301X

Stahl, G. (2006). Group cognition: Computer support for building collaborative knowledge. Cambridge: MIT Press.

Swain, M. (1985). Communicative competence: Some roles of comprehensible input and output in its development. In S. M. Gass, \& C. G. Madden (Eds.), Input and second language acquisition (pp. 115-132). Rowley, MA: Newbury House.

Thomas, M. K. (2005). The quest of Quest Atlantis: Developing a nuanced implementation of a technology rich educational innovation. Doctoral dissertation. The University of Indiana, Bloomington, IN.

Thorne, S. L., \& Reinhardt, J. (2008). "Bridging activities," new media literacies and advanced foreign language proficiency. The CALICO Journal, 25(3), 558-572.

Varonis, E., \& Gass, S. (1985). Non-native/non-native conversations: As model for negotiation, Applied Linguistics, 6, 71-90. http://dx.doi.org/10.1093/applin/6.1.71

Watson-Gegeo, K. A. (2004). Mind, language, and epistemology: Toward a language socialization paradigm for SLA, The Modern Language Journal, 88(3), 331-350. http://dx.doi.org/10.1111/j.0026-7902.2004.00233.x

Zheng, D. (2006). Affordances of $3 D$ virtual environments for English language learning: An ecological psychological analysis. Doctoral dissertation. University of Connecticut, Storrs, CT.

Zheng, D., Young, M. F., Wagner, M. M., \& Brewer, R. A. (2009). Negotiation for action: English language learning in game-based virtual worlds. The Modern Language Journal, 93(4), 489-511. http://dx.doi.org/10.1111/j.1540-4781.2009.00927.x

\section{Copyrights}

Copyright for this article is retained by the author(s), with first publication rights granted to the journal.

This is an open-access article distributed under the terms and conditions of the Creative Commons Attribution license (http://creativecommons.org/licenses/by/3.0/). 